\title{
Evaluation of diazepam adsorption in aqueous media using low-cost and natural zeolite: equilibrium and kinetics
}

\author{
Thaísa Frossard Coslop ${ }^{1} \cdot$ Ramiro Picoli Nippes ${ }^{1} \cdot$ Rosangela Bergamasco $^{1} \cdot$ Mara Heloisa Neves Olsen Scaliante $^{1}$
}

Received: 18 August 2021 / Accepted: 5 November 2021 / Published online: 16 November 2021

(c) The Author(s), under exclusive licence to Springer-Verlag GmbH Germany, part of Springer Nature 2021

\begin{abstract}
Diazepam has been detected in water sources around the world affecting the quality of drinking water. Even in small quantities, recent studies have proven the negative effects of the drug on human body. Since traditional water and sewage treatment do not remove this type of contaminant, it became interesting to evaluate forms to remove them from water sources. A cheap and eco-friendly alternative to remove this drug from the water is through adsorption using the natural clinoptilolite zeolite as an adsorbent. This work goal was to study the characterizations of clinoptilolite, such as scanning electron microscopy (SEM), energy-dispersive X-ray spectroscopy (EDS), X-ray diffractometer (XRD), and Fourier transform infrared spectroscopy (FTIR) and analyze the potential of this material as an adsorbent. Kinetic studies and isotherm analysis were performed in batch. The results showed the potential of the natural zeolite to remove the pollutant in an aqueous medium reaching a maximum adsorption capacity of $8.25 \mathrm{mg} \mathrm{g}^{-1}$. The adsorption process followed a pseudo-second-order kinetics indicating that the adsorption was based on a chemisorption process. The isotherms curves shown favorable adsorption and the Langmuir isotherm model fit the experimental data better.
\end{abstract}

Keywords Natural zeolite $\cdot$ Clinoptilolite $\cdot$ Characterization $\cdot$ Adsorption $\cdot$ PADs $\cdot$ Isotherm

\section{Introduction}

The contamination of water arrays by persistent and toxic compounds causes great concern in the scientific community since the risk that these substances represent to the environment. Among these contaminants, psychoactive drugs (PADs) are considered the most concentrated and frequently detected contaminants in various environmental matrices (Thiebault and Boussafir 2019).

One of the most applied PADs in medicine is the benzodiazepine diazepam (DZP), frequently used in the treatment of seizures, anxiety, muscle spasms, and insomnia, and it is one of the most dangerous compounds, due to its ability to bioaccumulate and generate toxic metabolites. Therefore,

Responsible Editor: Tito Roberto Cadaval Jr.

Thaísa Frossard Coslop

fcthaisa@gmail.com

1 Chemical Engineering Department, State University of Maringa, Av. Colombo, 5790, Zona 7, Maringá, PR, Brazil chronic exposure to this drug has been studied in aquatic organisms and shows negative effects even at low concentrations (Laws et al. 2011; Luján-Facundo et al. 2019). In addition, the problem involving DZP can be aggravated by the growing consumption of anxiolytic drugs, especially during the COVID-19 pandemic, in which the effect of quarantine and social isolation caused an increase in cases of anxiety, insomnia, and depression in the population generally (Saidi et al. 2021; Wu et al. 2021).

It is also worth noting that the DZP is on the model list of essential drugs of the world health organization for pain and anxiety control (Pettus et al. 2020). In this sense, the increased consumption of DZP, associated with its incomplete removal in wastewater treatment plants (WWTPs) (Gao et al. 2012; Organización Mundial de la Salud (OMS) 2019) leads the study of efficient and economically viable solutions that can improve the treatment of wastewater treatment plants. Among the techniques already used, the adsorption process is notable because of its generally low cost, ease of operation, and high efficiency (Fakhri and Adami 2014; Sani et al. 2016, 2017; Saleh 2020, 2021). However, for its effectiveness and viability, it is necessary to choose a low-cost 
adsorbent, with high adsorption capacity and selectivity (Thiebault and Boussafir 2019).

In this context, the natural clinoptilolite zeolite becomes a potential adsorbent, as it is a hydrophilic material with a promising adsorption capacity along with high abundance and relatively low costs and has been the object of study for different organic molecules (Lam et al. 1998, 2001; Mohseni et al. 2016). Therefore, this natural material may be a suitable candidate for the adsorption of the drug DZP in its natural form.

The adsorption of the drug diazepam was investigated in adsorbents, such as clay minerals (Thiebault and Boussafir 2019; Thiebault et al. 2019), hydrogel (Mota and Fajardo 2021), and activated carbon (Sulaiman et al. 2016; LujánFacundo et al. 2019). The use of zeolite CP in the removal of DZP has not yet been investigated. In addition to being natural, the use of $\mathrm{CP}$ as adsorbent does not require several changes in its structure. Therefore, the study of the efficiency of this material as an adsorbent in the removal of DZP from aqueous solutions under different conditions is of great importance, especially the study of the efficiency of this material as an adsorbent in the removal of DZP from aqueous solutions under different conditions.

From the above, the aim of this study is to investigate the use of the natural zeolite $\mathrm{CP}$ as an adsorbent for the removal of the benzodiazepine DZP in an aqueous system and to evaluate important process parameters, which are the adsorption equilibrium and the process kinetics and isotherms.

\section{Materials and methods}

The natural zeolite used as adsorbent was kindly provided by Celta Brasil, which is located on Vila Jovina-Cotia/SP, $06,705,150$. It was a clinoptilolite type mainly composed of $\mathrm{SiO}_{2}$ and $\mathrm{Al}_{2} \mathrm{O}_{3}$. Diazepam (99\%) was obtained from SigmaAldrich. The adsorption tests were run with distilled water.

\section{Preparation and characterization of the adsorbent}

Before the experimental tests, the zeolite was washed with deionized water in an ultrasound bath to remove the impurities, and oven dried and sieved $(0.4-1.0 \mathrm{~mm})$. The CP zeolite was characterized from textural analysis through N2 physisorption at $77 \mathrm{~K}$, using Micromeritics (model: ASAP 2020), using approximately $0.1 \mathrm{~g}$ of degassed zeolite at $300{ }^{\circ} \mathrm{C}$ for a period of $12 \mathrm{~h}$. The X-ray diffraction analysis was performed in a Bruker brand diffractometer, with an ion source copper scan speed of $2.0^{\circ} 2 \theta / \mathrm{min}$, from 5 to $65^{\circ} 2 \theta$, with a step size of $0.01^{\circ}$, voltage of $40 \mathrm{kV}$, and $30-\mathrm{mA}$ current. Infrared spectroscopy (FTIR) analysis was performed in a Bruker-Vertex 70 spectrophotometer in the range of 4000 to $400 \mathrm{~cm}^{-1}$ with 100 scans and a resolution of $4 \mathrm{~cm}^{-1}$. $\mathrm{KBr}$ was used as a reference, $100 \%$ transmittance, and for the analysis, $0.002 \mathrm{~g}$ of sample was weighed and mixed in $0.198 \mathrm{~g}$ of $\mathrm{KBr}$. To visualize the morphology of the samples of adsorbents, a scanning electron microscope Shimadzu SS-550 Superscan SS-550 software was used. For a qualitative analysis of how the chemical elements are distributed on the surface of the material, the EDS technique coupled to a scanning electron microscope was used.

\section{Adsorption experiments}

The adsorption experiments were carried out in batch and performed in triplicate, which makes the results more reliable. A shaker table was used (Shaker Cientec CT/712R) with a stirring speed of $200 \mathrm{rpm}$, temperature of $28{ }^{\circ} \mathrm{C}, 50 \mathrm{~mL}$ of DZP solution as adsorbate, and $0.1 \mathrm{~g}$ of $\mathrm{CP}$ zeolite as an adsorbent. The aliquots of each experiment were filtered using a stainless-steel holder and $0.22-\mu \mathrm{m}$ membranes, supplied by Millipore. The spectrophotometric analyzes were performed in a Shimadzu UV-VIS spectrophotometer (model UV-1800), through the calibration curve obtained at different concentrations of DZP and read through the absorbance at the maximum wavelength of $230 \mathrm{~nm}$ and determined by its respective calibration curve. The adsorbed amount was determined by the difference between the final and initial concentration of DZP using Eq. 1.

$q_{t}=\frac{\left(C_{0}-C_{e}\right) V}{m_{a}}$

where $q_{t}$ is the amount adsorbed per gram of adsorbent at equilibrium $\left(\mathrm{mg} \mathrm{g}^{-1}\right), C_{0}$ is the initial concentration of adsorbate $\left(\mathrm{mg} \mathrm{L}^{-1}\right), C_{\mathrm{e}}$ is the concentration of adsorbate at equilibrium $\left(\mathrm{m} \mathrm{L} \mathrm{L}^{-1}\right), V$ is the volume of solution $(\mathrm{L})$, and $m_{a}$ is the mass of adsorbent $(\mathrm{g})$.

To determine the adsorption kinetics of DZP in zeolite $\mathrm{CP}$, a volume of $50 \mathrm{~mL}$ of solution with a concentration of $25 \mathrm{mg} \mathrm{L}^{-1}$ of the contaminant and a mass of $0.1 \mathrm{~g}$ of zeolite, with removal of aliquots at time intervals, was used until the process reached equilibrium. The experimental data were applied to the non-linear kinetic adsorption models (Table S1) of pseudo-first-order (ESM Eq. 2), pseudosecond-order (ESM Eq. 3), Elovich (ESM Eq. 4), and the intraparticle diffusion model (ESM Eq. 5).

The adsorption isotherms were obtained by varying the contaminant concentration $(1,3,5,7,10,15,20$, and $25 \mathrm{mg}$ $\mathrm{L}^{-1}$ ) and applying $0.1 \mathrm{~g}$ of CP zeolite for each concentration. The results obtained were fitted to the non-linear isotherm models (Table S2) of Langmuir (ESM Eqs. 6 and 7), Freundlich (ESM Eq. 8), and Dubinin-Radushkevich (ESM Eqs. 9, 10 , and 11). 
Fig. 1 SEM images of the clinoptilolite sample: a $5000 \times$, $500 \mu \mathrm{m}$; and b $10,000 \times, 20 \mu \mathrm{m}$

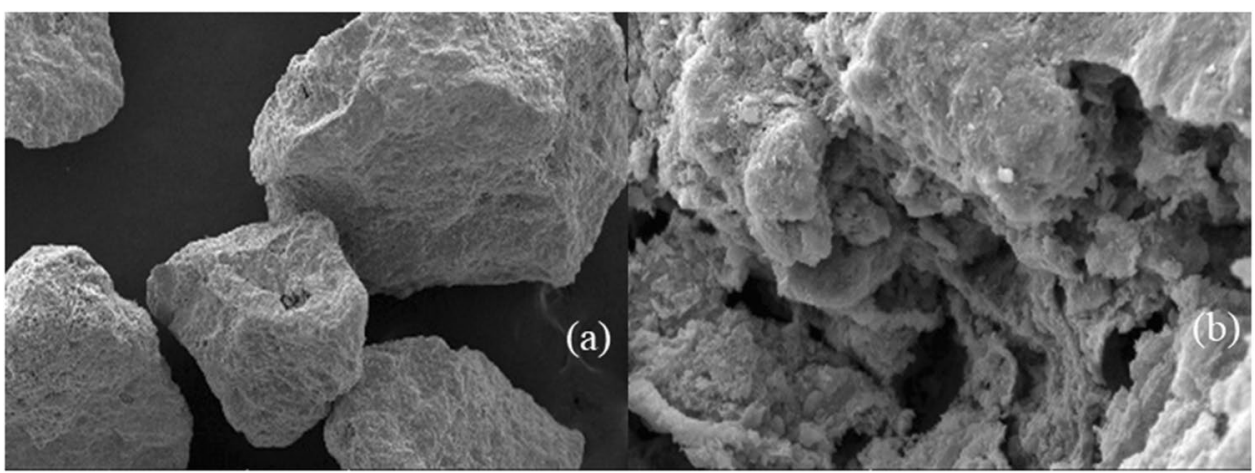

\section{Results and discussion}

\section{SEM}

The morphological surface of the CP made by SEM analysis is represented in Fig. 1a. It can be observed that the material does not present any standard structural organization such as expected. It is also possible to observe that the material has small cavities, represented by bright spots in Fig. 1b (Saleh 2015; Kussainova et al. 2019; Güngör and Özen 2021). The EDS analysis provides the percentage of components found on the surface of the material (A. Saleh and K. Gupta 2012) and is depicted in Fig. 2. The presence of expressive peaks of $\mathrm{Si}, \mathrm{O}$, and $\mathrm{Al}$ was detected, which confirms the main compounds of zeolite, but once this material was found in nature the presence of other elements is also expected, such as $\mathrm{Na}$ (Tran et al. 2019).

\section{XDR}

The XRD pattern of the clinoptilolite sample is presented in Fig. 3. Through X'Pert Highscore Plus Software, it was possible to identify the crystal structure and quantify the purity of the material. According to the Rietveld method, the characteristics peaks $2 \theta=9.8,11.1,22.3$, $22.7,26.0,28.1,30.0$, and $32.0^{\circ}$ of the sample diffractogram matched with Clinoptilolite (JCPDS sheet no. 00-025-1349), whose chemical formula is $(\mathrm{Na}, \mathrm{K}, \mathrm{Ca})_{6}$ $(\mathrm{Si}, \mathrm{Al})_{36} \mathrm{O}_{72} \cdot 20 \mathrm{H}_{2} \mathrm{O}$, and is in accordance with literature (Gottardi and Galli 1985; da Silva et al. 2021). Besides clinoptilolite, mordenite appeared as the second main phase, with $71.04 \%$ of clinoptilolite and $11.57 \%$ of mordenite. The material is monoclinic with the lattice unit cell parameters and has the following measurements: $a=17.6 \pm 0.01 \AA, b=17.9 \pm 0.01 \AA, c=7.39 \pm 0.02 \AA$, and $\beta=116.0 \pm 0.008^{\circ}$. The analysis also confirms the material as a mineral and inorganic zeolite.

\section{FTIR}

The infrared spectrum was used to identify the functional groups present in the zeolite by their specific vibration. (Saleh 2011) Through Fig. 4, it is possible to notice a band in the range of $3640-3620 \mathrm{~cm}^{-1}$ that can be associated with the vibration of free $\mathrm{O}-\mathrm{H}$ groups represented by water (Kavak and Ülkü 2013). In the range of $1750-1600 \mathrm{~cm}^{-1}$, it is noticed that the presence of vibration due to the presence
Fig. 2 EDS analysis of the natural zeolite $\mathrm{CP}$

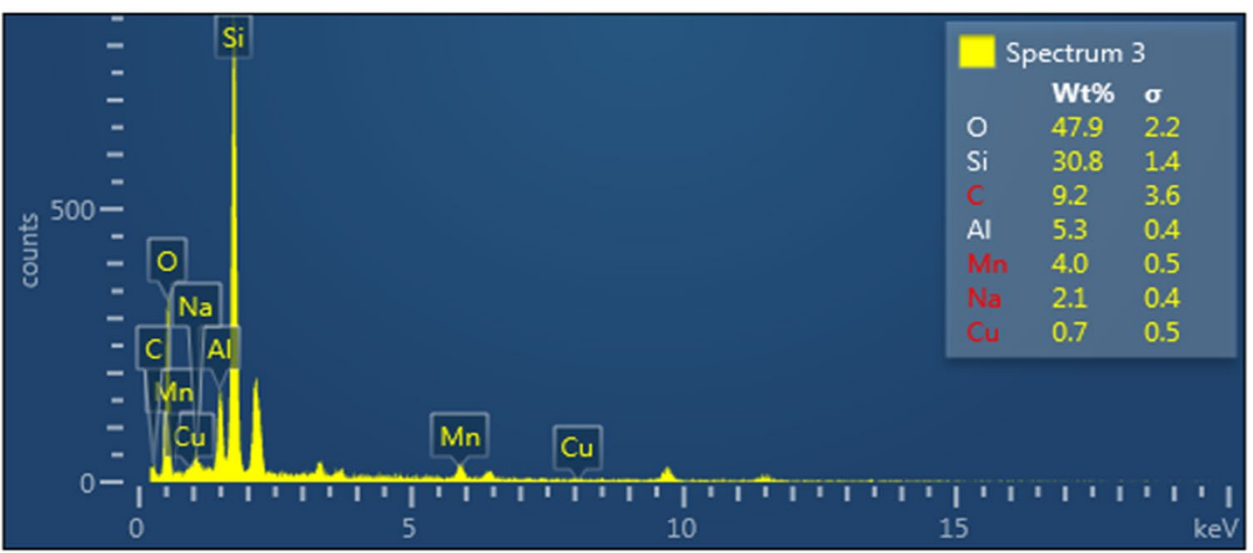




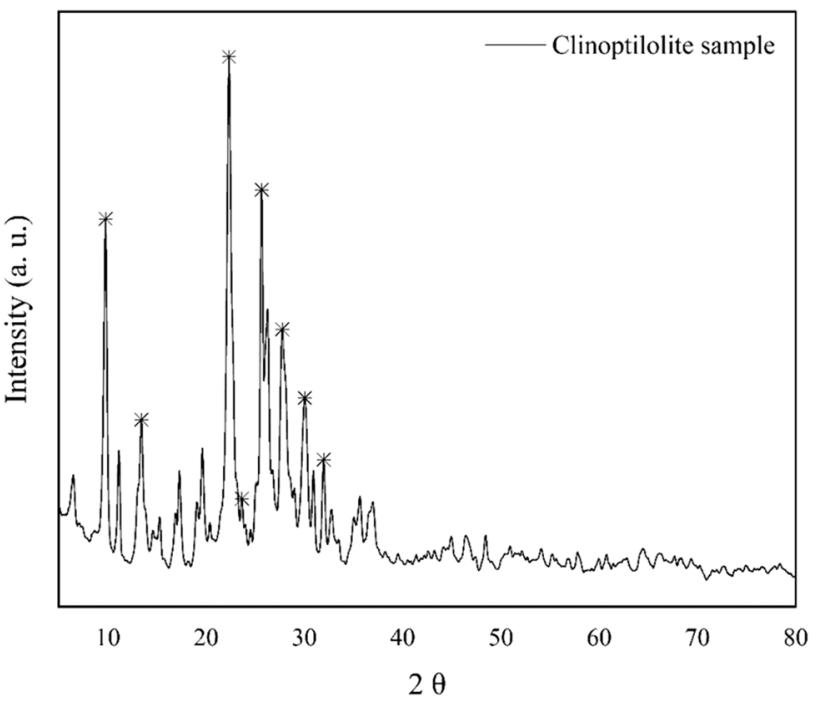

Fig. 3 XDR pattern of the zeolite clinoptilolite

of water adsorbed (Saleh 2018). The most intensive vibration frequency is between 1060 and $1040 \mathrm{~cm}^{-1}$, which is a result of the structural units of the alumina-silicate lattice $\mathrm{Si}$ (Al)-O of the zeolite, which confirms the main composition of the material used in this study (Favvas et al. 2016). In the range of $470-460 \mathrm{~cm}^{-1}$ a characteristic vibration of bicyclovibration of O-Si-O or O-Al-O was observed (Demirbüker Kavak and Ülkü 2015).

\section{Textural properties}

The values obtained for the specific area, pore-volume, pore diameters, and zero-point charge are shown in Table 1. The value for the specific area of the material

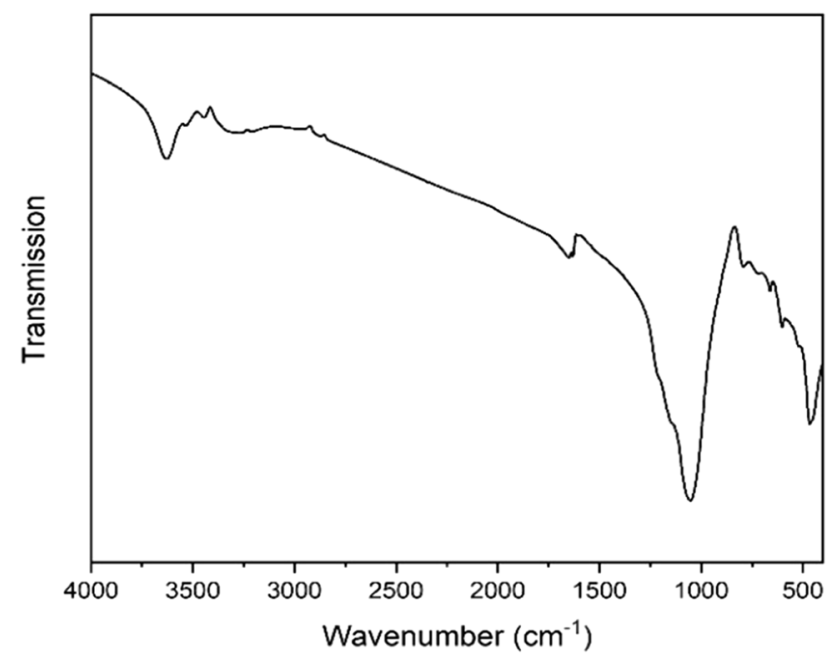

Fig. 4 FTIR spectra of the zeolite CP sample
Table 1 Texture parameters of the clinoptilolite sample

\begin{tabular}{lllll}
\hline Sample & $S_{\text {BET }}\left(\mathrm{m}^{2} / \mathrm{g}\right)$ & $V\left(\mathrm{~cm}^{3} / \mathrm{g}\right)$ & $d(\mathrm{~nm})$ & $\mathrm{pH}_{\mathrm{ZCP}}$ \\
\hline Clinoptilolite & 131.17 & 0.083 & 2.5 & 7.2 \\
\hline
\end{tabular}

was $128.12 \mathrm{~m}^{2} / \mathrm{g}$, a value higher than other studies that also used clinoptilolite zeolite (Akgül et al. 2006; Kennedy et al. 2019); this can be explained due to the variation of material characteristics accordingly with the region in which it is extracted. The pore diameter value indicates that it is a material with a predominantly mesoporous characteristic. However, according to the literature, clinoptilolite zeolite also presents characteristics of microporous adsorbents, in which there is a certain amount of impurities, especially clays, quartz, and amorphous vitreous material (Hernández et al. 2000). Regarding the $\mathrm{pH}_{\mathrm{zcp}}$ of the $C P$ reaching a value of 7.2 , it favors the adsorption of the DZP since the aqueous solution of DZP has a $\mathrm{pH}$ of 5.82 (da Silva et al. 2021).

\section{Kinetics of adsorption}

In Table 2 and Fig. 5a, the results of the adsorption kinetics of diazepam on CP natural zeolite are presented. The aim of the kinetic study is to determine the control mechanisms

Table 2 Parameters and determination coefficients of the non-linear kinetic models for diazepam adsorption

\begin{tabular}{|c|c|c|}
\hline Model & Parameter & $\begin{array}{l}\text { Temperature }(\mathrm{K}) \\
298\end{array}$ \\
\hline \multirow[t]{5}{*}{ Pseudo-first order } & $k_{1}\left(\min ^{-1}\right)$ & 0.013 \\
\hline & $q_{\mathrm{e}}\left(\mathrm{mg} \mathrm{g}^{-1}\right)$ & 8.862 \\
\hline & $\chi^{2}$ & 0.124 \\
\hline & $R^{2}$ & 0.989 \\
\hline & $R^{2}$ adj & 0.988 \\
\hline \multirow[t]{5}{*}{ Pseudo-second order } & $k_{2}\left(\mathrm{~g} \mathrm{mg}^{-1} \mathrm{~min}^{-1}\right)$ & 0.001 \\
\hline & $q_{\mathrm{e}}\left(\mathrm{mg} \mathrm{g}^{-1}\right)$ & 10.63 \\
\hline & $\chi^{2}$ & 0.047 \\
\hline & $R^{2}$ & 0.996 \\
\hline & $R^{2}$ adj & 0.995 \\
\hline \multirow[t]{5}{*}{ Elovich } & $\alpha\left(\mathrm{mg} \mathrm{g}^{-1} \min ^{-1}\right)$ & 0.277 \\
\hline & $\beta\left(\mathrm{g} \mathrm{mg}^{-1}\right)$ & 0.404 \\
\hline & $\chi^{2}$ & 0.186 \\
\hline & $R^{2}$ & 0.960 \\
\hline & $R^{2}$ adj & 0.959 \\
\hline \multirow[t]{5}{*}{ Intraparticle diffusion } & $K\left(\mathrm{mg} \mathrm{g}^{-1} \min ^{-0.5}\right)$ & 1.957 \\
\hline & $C\left(\mathrm{mg} \mathrm{g}^{-1}\right)$ & 0.989 \\
\hline & $\chi^{2}$ & 0.007 \\
\hline & $R^{2}$ & 0.907 \\
\hline & $R^{2}$ adj & 0.898 \\
\hline
\end{tabular}



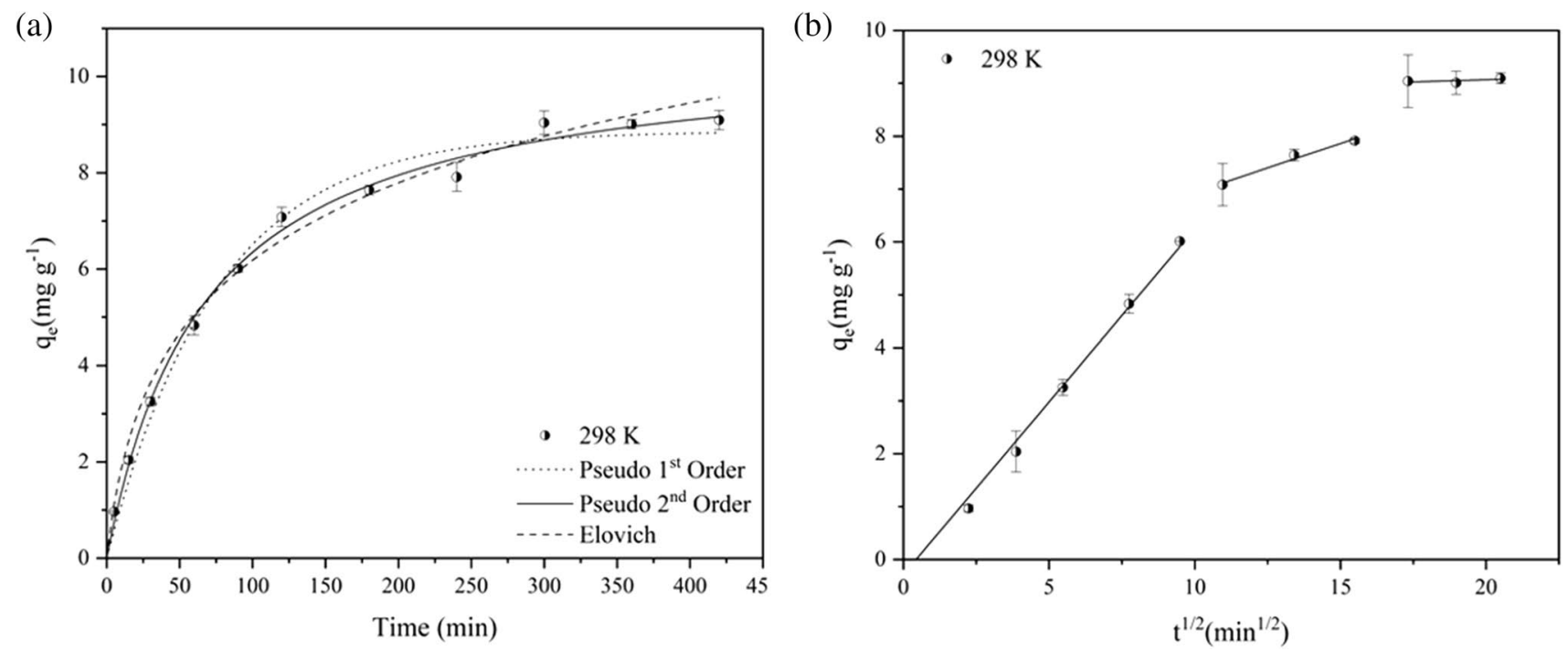

Fig. 5 Kinetic curve for adsorption of diazepam on CP zeolite at $298 \mathrm{~K}$ with fit to the a pseudo-first-order, pseudo-second-order, and Elovich models, and $\mathbf{b}$ fit to the intraparticle diffusion model

of adsorption processes (processes such as surface adsorption, chemical reaction) or diffusion mechanisms and also to determine the time needed to complete the adsorption process and its speed, which is useful for design models for the process. It is possible to observe that in the studied process, the adsorption occurred more intensely in the first $60 \mathrm{~min}$, due to the greater availability of sites on the zeolite surface, and the equilibrium of the adsorption process is reached around $300 \mathrm{~min}$. The shape of the kinetic shows the affinity between the adsorbent and the adsorbate.

According to the results of the kinetic studies, it can be verified that the adsorption kinetics of diazepam by zeolite $\mathrm{CP}$ can be better described by the pseudo-second-order kinetics model, according to the calculated statistical parameters, available in Table 2. This indicates that the adsorption process is based on a chemisorption process of diazepam present in the aqueous solution to the surface of the adsorbent, due to a physical-chemical interaction, since the hydrophilic characteristic of the zeolite favors this type of interaction (Gupta et al. 2018).

The intraparticle diffusion model is used to understand the mechanisms that may be involved in the adsorption process. Figure $5 b$ shows the fit of the intraparticle diffusion model for adsorption of diazepam on zeolite $\mathrm{CP}$, in which it is possible to visualize a multilinearity in the adsorption process, indicating that two or more steps can occur and that the intraparticle diffusion mechanism is not dominant. The first step between 0 and $10 \mathrm{~min}^{1 / 2}$ refers to the boundary layer effect, with external mass transfer, in which DZP is rapidly adsorbed by the CP zeolite. The second step concerns the diffusion of molecules to the adsorbent's innermost adsorption sites. Finally, in the last step, there is an equilibrium where intraparticle diffusion decreases due to the low concentration of solute in the solution as well as lower availability of sites for adsorption (Calisto et al. 2019; Babas et al. 2021).

\section{Adsorption isotherms}

To investigate the phenomena that occurred at the surface of CP during the adsorption process, three models were applied: Langmuir, Freundlich, and Dubnin-Radushkevich. Figure 6 shows the equilibrium isotherms obtained

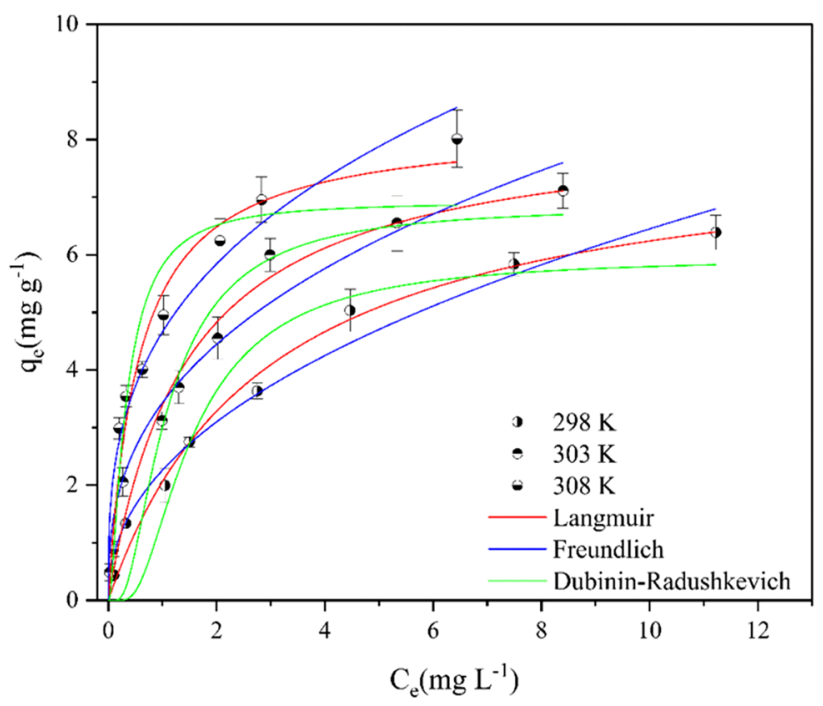

Fig. 6 Equilibrium isotherms for DZP adsorption at temperatures of 298, 303, and $308 \mathrm{~K}$ 
for temperatures of 298,303 , and $308 \mathrm{~K}$. It is possible to observe that due to a strong influence of temperature, showing that the adsorption of DZP consists of an endothermic process.

The fitting plots for each isotherm model are shown in Fig. 6 and it is possible to see an L1 type of isotherm according to (Giles et al. 1964) which configures that the ratio between the concentration of the compound in the solution and adsorbed on the solid decreases when the concentration of solute increases.

The calculated parameters summarized in Table 3 indicates that Freundlich and Dubinin-Radushkevich models did not fit as well as Langmuir, which reached a good correlation coefficient $\left(R^{2}\right)$ and also presented a lower value of chi-square $\left(\chi^{2}\right)$ indicating that this model brings a better approximation between theoretical and experimental data. The better adjustment of the experimental data for the Langmuir isotherm model suggests that the adsorbent used exhibits finite numbers of identical active sites available for interaction with the adsorbate and there is no side interaction due to steric hindrance between the adsorbed molecules on the surface (Paudyal et al. 2020). It is also worth mentioning that the values referring to the $k_{\mathrm{L}}$ parameter increased with temperature, indicating that the temperature favored adsorption (Ghabbour and Davies 2011; Mohseni et al. 2016).

The parameter $\mathrm{n}$ of the Freundlich model at all 3 temperatures still indicates that the adsorption process was

Table 3 Parameters and coefficients of the non-linear isotherms for DZP adsorption

\begin{tabular}{lllll}
\hline Model & Parameters & \multicolumn{3}{l}{ Temperature $(\mathrm{K})$} \\
\cline { 3 - 5 } & & 298 & 303 & 308 \\
\hline Langmuir & $Q_{\max }\left(\mathrm{mg} \mathrm{g}^{-1}\right)$ & 8.051 & 8.348 & 8.259 \\
& $k_{\mathrm{l}}\left(\mathrm{L} \mathrm{mg}^{-1}\right)$ & 0.344 & 0.684 & 1.823 \\
& $R_{\mathrm{L}}$ & 0.373 & 0.979 & 0.847 \\
& $R^{2}$ & 0.990 & 0.980 & 0.972 \\
& $R^{2}$ adj & 0.988 & 0.977 & 0.969 \\
& $\chi^{2}$ & 0.061 & 0.147 & 0.221 \\
& $k_{\mathrm{f}}\left(\mathrm{mg} \mathrm{g}^{-1}\right)$ & 0.154 & 3.430 & 4.658 \\
& $n$ & 0.172 & 2.674 & 3.063 \\
& $R^{2}$ & 0.982 & 0.976 & 0.956 \\
& $R^{2} \mathrm{adj}^{2}$ & 0.980 & 0.972 & 0.950 \\
& $\chi^{2}$ & 0.107 & 0.178 & 0.356 \\
& $Q_{\text {max }}\left(\mathrm{mg} \mathrm{g}^{-1}\right)$ & 5.953 & 6.841 & 6.908 \\
& $k\left(\mathrm{~mol}^{2} \mathrm{~J}^{-2}\right)$ & $4 \mathrm{E}-7$ & $2 \mathrm{E}-7$ & $5 \mathrm{E}-8$ \\
& $E\left(\mathrm{~kJ} \mathrm{~mol}^{-1}\right)$ & 1.118 & 1.581 & 3.162 \\
$R^{2}$ & 0.915 & 0.911 & 0.931 \\
& $R^{2}$ adj & 0.915 & 0.898 & 0.921 \\
$\chi^{2}$ & 0.460 & 0.667 & 0.563 \\
\hline
\end{tabular}

strongly favorable under the investigated conditions, demonstrating the affinity between the adsorbent and adsorbate. Furthermore, the calculated values of $1 / n>1$ suggest that the adsorbent works well for solutions with a high concentration of the contaminant (Sarat Chandra et al. 2015).

Regarding the parameters calculated on D-R model, it can be noticed that the values obtained for $E$, for all temperatures tested, were below $8 \mathrm{~kJ} \mathrm{~mol}^{-1}$ indicating that the adsorption process of DZP on CP was of physical nature (Sari and Tuzen 2009).

\section{Conclusion}

The present study suggests that a natural clinoptilolite can be effectively used as an absorbent for the removal of psychotropic drug diazepam from aqueous matrices. In this study, the importance of clinoptilolite morphology in the use of the adsorption process is clear and also confirmed through SEM, FTIR, and XDR analysis. According to the calculations, the adsorbed amount of the contaminant ranged from 8.05 to $8.25 \mathrm{mg} \mathrm{g}^{-1}$. The kinetic model of pseudo-secondorder fits better to the experimental data, indicating that it is a process with contribution of chemisorption. Langmuir was the isotherm model that best fit the experimental equilibrium data, whose parameters showed that it is strongly favorable adsorption.

Supplementary Information The online version contains supplementary material available at https://doi.org/10.1007/s11356-021-17452-z.

Acknowledgements The authors acknowledge the Coordination for Personal Improvement and Higher Education (CAPES) for financial support, Celta Brasil for providing the samples, and State University of Maringá for technical support to conduct this research.

Author contribution TFC: investigation; formal analysis and writing. RPN: conceptualization and writing.

RB: resources.

MHNOS: supervision and writing-review.

Funding This study was financially supported by Coordination for Personal Improvement and Higher Education (CAPES): scholarship.

Data Availability The datasets used and/or analyzed during the current study are available from the corresponding author on reasonable request.

\section{Declarations}

Ethics approval and consent to participate Not applicable.

Consent for publication Not applicable.

Competing interests The authors declare no competing interests. 


\section{References}

A. Saleh T, K. Gupta V (2012) Characterization of the Chemical Bonding between $\mathrm{Al} 2 \mathrm{O} 3$ and nanotube in MWCNT/ $\mathrm{Al} 2 \mathrm{O} 3$ nanocomposite. Curr Nanosci 8:739-743. https://doi.org/10.2174/15734 1312802884418

Akgül M, Karabakan A, Acar O, Yürüm Y (2006) Removal of silver (I) from aqueous solutions with clinoptilolite. Microporous Mesoporous Mater 94:99-104. https://doi.org/10.1016/j.micro meso.2006.02.023

Babas H, Kaichouh G, Khachani M et al (2021) Equilibrium and kinetic studies for removal of antiviral sofosbuvir from aqueous solution by adsorption on expanded perlite: experimental, modelling and optimization. Surfaces and Interfaces 23:100962. https://doi.org/ 10.1016/j.surfin.2021.100962

Calisto JS, Pacheco IS, Freitas LL et al (2019) Adsorption kinetic and thermodynamic studies of the 2,4-dichlorophenoxyacetate $(2,4-\mathrm{D})$ by the $[\mathrm{Co}-\mathrm{Al}-\mathrm{Cl}]$ layered double hydroxide. Heliyon 5:e02553. https://doi.org/10.1016/j.heliyon.2019.e02553

da Silva PL, Nippes RP, Macruz PD et al (2021) Photocatalytic degradation of hydroxychloroquine using $\mathrm{ZnO}$ supported on clinoptilolite zeolite. Water Sci Technol 84:763-776. https://doi.org/10. 2166/wst.2021.265

Demirbüker Kavak D, Ülkü S (2015) Kinetic and equilibrium studies of adsorption of $\beta$-glucuronidase by clinoptilolite-rich minerals. Process Biochem 50:221-229. https://doi.org/10.1016/j.procbio. 2014.12.013

Fakhri A, Adami S (2014) Adsorption and thermodynamic study of cephalosporins antibiotics from aqueous solution onto $\mathrm{MgO}$ nanoparticles. J Taiwan Inst Chem Eng 45:1001-1006. https://doi.org/ 10.1016/j.jtice.2013.09.028

Favvas EP, Tsanaktsidis CG, Sapalidis AA et al (2016) Clinoptilolite, a natural zeolite material: structural characterization and performance evaluation on its dehydration properties of hydrocarbonbased fuels. Microporous Mesoporous Mater 225:385-391. https://doi.org/10.1016/j.micromeso.2016.01.021

Gao P, Ding Y, Li H, Xagoraraki I (2012) Occurrence of pharmaceuticals in a municipal wastewater treatment plant: mass balance and removal processes. Chemosphere 88:17-24. https://doi.org/ 10.1016/j.chemosphere.2012.02.017

Ghabbour EA, Davies G (2011) Environmental insights from Langmuir adsorption site capacities. Colloids Surfaces A Physicochem Eng Asp 381:37-40. https://doi.org/10.1016/j.colsurfa.2011.03.014

Giles CH;, Easton IA; McKay R. (1964) Mechanism of adsorption of cationic dyes by alumina, and a note on heat changes in solution adsorption J ChemSoc 4492-4495. https://doi.org/10.1016/b9780-12-309650-0.50007-7

Gottardi G, Galli E (1985) In natural zeolites

Güngör D, Özen S (2021) Development and characterization of clinoptilolite-, mordenite-, and analcime-based geopolymers: a comparative study Case Stud Constr Mater 15. https://doi.org/10.1016/j. cscm.2021.e00576

Gupta VK, Fakhri A, Agarwal S et al (2018) Preparation and characterization of $\mathrm{TiO} 2$ nanofibers by hydrothermal method for removal of benzodiazepines (diazepam) from liquids as catalytic ozonation and adsorption processes. J Mol Liq 249:1033-1038. https://doi. org/10.1016/j.molliq.2017.11.144

Hernández MA, Rojas F, Lara VH (2000) Nitrogen-sorption characterization of the microporous structure of clinoptilolite-type zeolites. J Porous Mater 7:443-454. https://doi.org/10.1023/A: 1009662408173

Kavak DD, Ülkü S (2013) Investigation of structural properties of clinoptilolite rich zeolites in simulated digestion conditions and their cytotoxicity against Caco-2 cells in vitro. J Porous Mater 20:331-338. https://doi.org/10.1007/s10934-012-9602-1
Kennedy DA, Mujčin M, Abou-Zeid C, Tezel FH (2019) Cation exchange modification of clinoptilolite -thermodynamic effects on adsorption separations of carbon dioxide, methane, and nitrogen. Microporous Mesoporous Mater 274:327-341. https://doi. org/10.1016/j.micromeso.2018.08.035

Kussainova MZ, Chernyakova RM, Jussipbekov UZ, Paşa S (2019) Structural investigation of raw clinoptilolite over the $\mathrm{Pb} 2+$ adsorption process from phosphoric acid. J Mol Struct 1184:49 58. https://doi.org/10.1016/j.molstruc.2019.02.012

Lam A, Rivera A, Rodrídguez-Fuentes G (2001) Theoretical study of metronidazole adsorption on clinoptilolite. Microporous Mesoporous Mater 49:157-162. https://doi.org/10.1016/S13871811(01)00413-9

Lam A, Sierra LR, Rojas G et al (1998) Theoeretical study of the physical adsorption of aspirin on natural clinoptilolite. Microporous Mesoporous Mater 23:247-252. https://doi.org/10.1016/S13871811(98)00060-2

Laws BV, Dickenson ERV, Johnson TA et al (2011) Attenuation of contaminants of emerging concern during surface-spreading aquifer recharge. Sci Total Environ 409:1087-1094. https://doi.org/10. 1016/j.scitotenv.2010.11.021

Luján-Facundo MJ, Iborra-Clar MI, Mendoza-Roca JA, AlcainaMiranda MI (2019) Pharmaceutical compounds removal by adsorption with commercial and reused carbon coming from a drinking water treatment plant J Clean Prod 238. https://doi.org/ 10.1016/j.jclepro.2019.117866

Mohseni SN, Amooey AA, Tashakkorian H, Amouei AI (2016) Removal of dexamethasone from aqueous solutions using modified clinoptilolite zeolite (equilibrium and kinetic). Int J Environ Sci Technol 13:2261-2268. https://doi.org/10.1007/ s13762-016-1045-9

Mota HP, Fajardo AR (2021) Development of superabsorbent hydrogel based on Gum Arabic for enhanced removal of anxiolytic drug from water J Environ Manage 288. https://doi.org/10.1016/j.jenvm an.2021.112455

Organización Mundial de la Salud (OMS) (2019) World health organization model list of essential medicines. Ment Holist Heal Some Int Perspect 21:119-134

Paudyal S, Sharma SK, da Silva RLCG et al (2020) Tyrosinase enzyme Langmuir monolayer: surface chemistry and spectroscopic study. J Colloid Interface Sci 564:254-263. https://doi.org/10.1016/j.jcis. 2019.12.118

Pettus K, Cleary JF, Lima L et al (2020) Availability of internationally controlled essential medicines in the COVID-19 pandemic. J Pain Symptom Manage 60:e48-e51. https://doi.org/10.1016/j. jpainsymman.2020.04.153

Saidi I, Koumeka PP, Ait Batahar S, Amro L (2021) Factors associated with anxiety and depression among patients with Covid-19 Respir Med 186. https://doi.org/10.1016/j.rmed.2021.106512

Saleh TA (2021) Protocols for synthesis of nanomaterials, polymers, and green materials as adsorbents for water treatment technologies. Environ Technol Innov 24:101821. https://doi.org/10.1016/j. eti.2021.101821

Saleh TA (2020) Nanomaterials: classification, properties, and environmental toxicities. Environ Technol Innov 20:101067. https:// doi.org/10.1016/j.eti.2020.101067

Saleh TA (2015) Isotherm, kinetic, and thermodynamic studies on $\mathrm{Hg}(\mathrm{II})$ adsorption from aqueous solution by silica- multiwall carbon nanotubes. Environ Sci Pollut Res 22:16721-16731. https:// doi.org/10.1007/s11356-015-4866-z

Saleh TA (2011) The influence of treatment temperature on the acidity of MWCNT oxidized by HNO 3 or a mixture of HNO $3 / \mathrm{H} 2$ SO 4. Appl Surf Sci 257:7746-7751. https://doi.org/10.1016/j. apsusc.2011.04.020

Saleh TA (2018) Simultaneous adsorptive desulfurization of diesel fuel over bimetallic nanoparticles loaded on activated carbon. 
J Clean Prod 172:2123-2132. https://doi.org/10.1016/j.jclepro. 2017.11.208

Sani HA, Ahmad MB, Hussein MZ et al (2017) Nanocomposite of ZnO with montmorillonite for removal of lead and copper ions from aqueous solutions. Process Saf Environ Prot 109:97-105. https:// doi.org/10.1016/j.psep.2017.03.024

Sani HA, Ahmad MB, Saleh TA (2016) Synthesis of zinc oxide/talc nanocomposite for enhanced lead adsorption from aqueous solutions. RSC Adv 6:108819-108827. https://doi.org/10.1039/c6ra2 $4615 \mathrm{j}$

Sarat Chandra T, Mudliar SN, Vidyashankar S et al (2015) Defatted algal biomass as a non-conventional low-cost adsorbent: surface characterization and methylene blue adsorption characteristics. Bioresour Technol 184:395-404. https://doi.org/10.1016/j.biort ech.2014.10.018

Sari A, Tuzen M (2009) Biosorption of As(III) and As(V) from aqueous solution by macrofungus (Inonotus hispidus) biomass: equilibrium and kinetic studies. J Hazard Mater 164:1372-1378. https://doi.org/10.1016/j.jhazmat.2008.09.047

Sulaiman S, Khamis M, Nir S et al (2016) Diazepam stability in wastewater and removal by advanced membrane technology, activated carbon, and micelle-clay complex. Desalin Water Treat 57:3098 3106. https://doi.org/10.1080/19443994.2014.981225
Thiebault T, Boussafir M (2019) Adsorption mechanisms of psychoactive drugs onto montmorillonite. Colloids Interface Sci Commun 30:100183. https://doi.org/10.1016/j.colcom.2019.100183

Thiebault T, Boussafir M, Fougère L, et al (2019) Clay minerals for the removal of pharmaceuticals: initial investigations of their adsorption properties in real wastewater effluents Environ Nanotechnology, Monit Manag 12. https://doi.org/10.1016/j.enmm. 2019.100266

Tran YT, Lee J, Kumar P et al (2019) Natural zeolite and its application in concrete composite production. Compos Part B 165:354-364. https://doi.org/10.1016/j.compositesb.2018.12.084

Wu T, Jia X, Shi H et al (2021) Prevalence of mental health problems during the COVID-19 pandemic: a systematic review and metaanalysis. J Affect Disord 281:91-98. https://doi.org/10.1016/j.jad. 2020.11.117

Publisher's note Springer Nature remains neutral with regard to jurisdictional claims in published maps and institutional affiliations. 